\title{
Article \\ Study of the Association between Postural Misalignments in School Students
}

\author{
João Pedro Gouveia ${ }^{1, *(\mathbb{D}}$, Pedro Forte ${ }^{2,3,4} \mathbb{( D}$, Joana Ribeiro ${ }^{3}$ and Eduarda Coelho , $^{1,2}$ \\ 1 Department of Sports Sciences, Health and Exercise, University of Trás-os-Montes e Alto Douro, Edifício de \\ Ciências do Desporto, Quinta de Prados, 5001-801 Vila Real, Portugal; ecoelho@utad.pt \\ 2 Research Center in Sports, Health and Human Development, CIDESD, 6201-001 Covilhã, Portugal; \\ pedromiguel.forte@iscedouro.pt \\ 3 Department of Sports, Douro Higher Institute of Educational Sciences of the Douro, Rua Vitorino da Costa, \\ $\mathrm{N}^{\circ} 46,4560-708$ Penafiel, Portugal; joana.ribeiro@iscedouro.pt \\ 4 Department of Sports Sciences and Physical Education, Instituto Politécnico de Bragança, \\ 5300-253 Bragança, Portugal \\ * Correspondence: joaopsgouveia@gmail.com; Tel.: +351-91-840-9153
}

Citation: Gouveia, J.P.; Forte, P.; Ribeiro, J.; Coelho, E. Study of the Association between Postural Misalignments in School Students. Symmetry 2021, 13, 1959. https:// doi.org/10.3390/sym13101959

Academic Editor: Anna Mika; Łukasz Oleksy

Received: 24 September 2021

Accepted: 14 October 2021

Published: 18 October 2021

Publisher's Note: MDPI stays neutral with regard to jurisdictional claims in published maps and institutional affiliations.

Copyright: (c) 2021 by the authors. Licensee MDPI, Basel, Switzerland. This article is an open access article distributed under the terms and conditions of the Creative Commons Attribution (CC BY) license (https:// creativecommons.org/licenses/by/ $4.0 /)$.

\begin{abstract}
Nowadays, postural misalignments prevalence in students is increasingly evident and its early detection is the best way to prevent complications in adulthood. It is also known that postural problems appear to have association between them. The aim of this study was to characterize and study the association between spine, scapular and pelvic girdles postural misalignments in 213 school students (124 males and 89 females), aged between 10 and 20 years, from Escola Básica e Secundária de Santa Maria (EBSSM). To understand the relation between postural misalignments we compare the head positioning with the shoulder girdle, the shoulder girdle with the dorsal spine and the lumbar spine with the pelvic girdle. The postural assessment was made by visual scan analysis in a symmetrograph based on photogrammetry and the Adams. We found high percentages of postural misalignments in all subjects. High prevalence was observed in the posterior view of the frontal plane in the head lateral flexion, shoulders vertical asymmetry, scoliosis and in the presence of gibbosity, whereas, in the right view of the sagittal plane forward head posture and protracted shoulders were observed. The lumbar scoliosis was more prevalent in subjects with iliac crest's asymmetry $(p<0.001)$ and forward head posture was significantly related to the subjects with protracted shoulders $(\mathrm{p}=0.010)$. The protracted shoulders were more prevalent in subjects with dorsal hyperkyphosis $(p=0.048)$ and lumbar hyperlordosis was related to the subjects with pelvic anteversion $(p<0.001)$. The students' postural assessment showed a wide variety of postural misalignments. It also seems evident that there is a relationship between their occurrences. It should be highlighted the importance of postural assessment in physical education (PE) classes to determine postural misalignments among school students.
\end{abstract}

Keywords: postural misalignments; physical education; adolescents and youngsters

\section{Introduction}

Posture is recognizable as a body position in each activity. It is defined by the joints and body segments relative positions [1]. The optimal postural alignment that leads to an optimal movement efficiency result from minimal tension in the body's structures [2]. Physical activities and postural behavior modifications in the bones positions may be related with muscle shortening that could result in musculoskeletal system overloads [3]. Upon that, school environment and occupational activity might be associated with the student's posture.

The adoption and embracing of postural behaviors in humans being starts in the earliest ages [4]. Musculoskeletal system postural changes may lead to degenerative pathologies and, if not earlier identified and adjusted, may physically limit the individuals [5]. There is 
numerous evidence that postural misalignments are present at all school ages [6-12], with a higher prevalence of forward head posture, protracted shoulders and scoliosis [3,13-15].

Posture in students could be affected by school surroundings, that act similar to a potential external factor that may contribute to postural misalignments. [9]. Furthermore, and due to the long time spent at school, children and adolescents' bone and muscle growth and development might be affected by postural habits adopted there $[3,6,9,12,13,16]$. This finding is reinforced by prolong daily inactivity periods in the classroom adopting incorrect postures of their body segments and the lack of the necessary ergonomic adaptation of school environment, that do not take into account the anthropometric dimensions of users in different age groups [7,9,15-20]. The schoolbag weight is often excessive [21] and its transportation is also mostly carried out asymmetrically [22]. Students with misaligned sitting and standing postures were also more likely to present low back pain [18]. Thus, school environment may change postural behavior and alignment in students.

Consequently, student's postural assessment in physical education (PE) classes may be the best way for the early detection of postural misalignments $[17,23,24]$. In this manner $\mathrm{PE}$ teachers acquire, in collaboration with health professionals, a meaningful role in public health promotion [25]. Additionally, and based on the student's postural misalignments, PE teachers should develop exercises that not only consider these pathologies, but also contribute to their correction and normalization [9,11]. Postural assessment is also admissible in all ages due to the growing and ageing processes $[8,11]$. There also seems to be a tendency that postural behavior acquired during early ages may remain till adulthood [11,22].

Postural assessment is possible to be carried out through different methods, such as photogrammetry, tomography, X-ray, plumb lines, visual scan analysis, symmetrographs questionnaires, goniometers and scoliometers $[9,17]$. The symmetrograph is a non-invasive method that showed to be valid and reliable for postural assessment in young students, being the most used in large samples and in the school context $[9,19,26]$. The Adams Test is universally accepted as the primary means of identifying scoliosis $[5,27]$. Up to date, it is known that postural problems appear to have association between them, however, the studies evidence a lack of precision in the clear identification of the existing association among postural problems, namely related with scoliosis.

Thus, the aim of this study was to assess spine, scapular and pelvic alignment by visual scan analysis, in order to detect postural misalignments in these body segments. It was hypothesized that the subjects would show high percentages of postural misalignments and that there is a relationship between its occurrences.

\section{Materials and Methods}

\subsection{Participants}

This study encompassed 213 students, 124 males and 89 females, aged between 10 and 20 years, with an average age of $14.30 \pm 2.65$ years. We can assume the representativeness of the sample in relation to the local student population. All assessments were performed at the Escola Básica e Secundária de Santa Maria in PE classes. A request for authorization was previously sent to the parents or guardians, as well as an explanation of the study methodology and the importance of the students' postural assessment. The study was approved by the Education Regional Direction with process number DSP/15-29 and the procedures were in accordance with the Helsinki Declaration regarding human research.

\subsection{Visual Scan Analysis}

The field test was made by visual scan analysis with a symmetrograph. The symmetograph had a transparent acrylic plate with $2 \mathrm{~m}$ high and $1 \mathrm{~m}$ wide, inserted in a wooden frame, containing a 0.1 square grid metric (Figure 1). The fabrication of the symmetrograph was based on Kendall's studies [28]. A $0.6 \mathrm{~m} \times 0.6 \mathrm{~m}$ wooden base was connected to the symmetrograph for foot placement, without any positional references. The subjects were told to position themselves precisely in the center. 

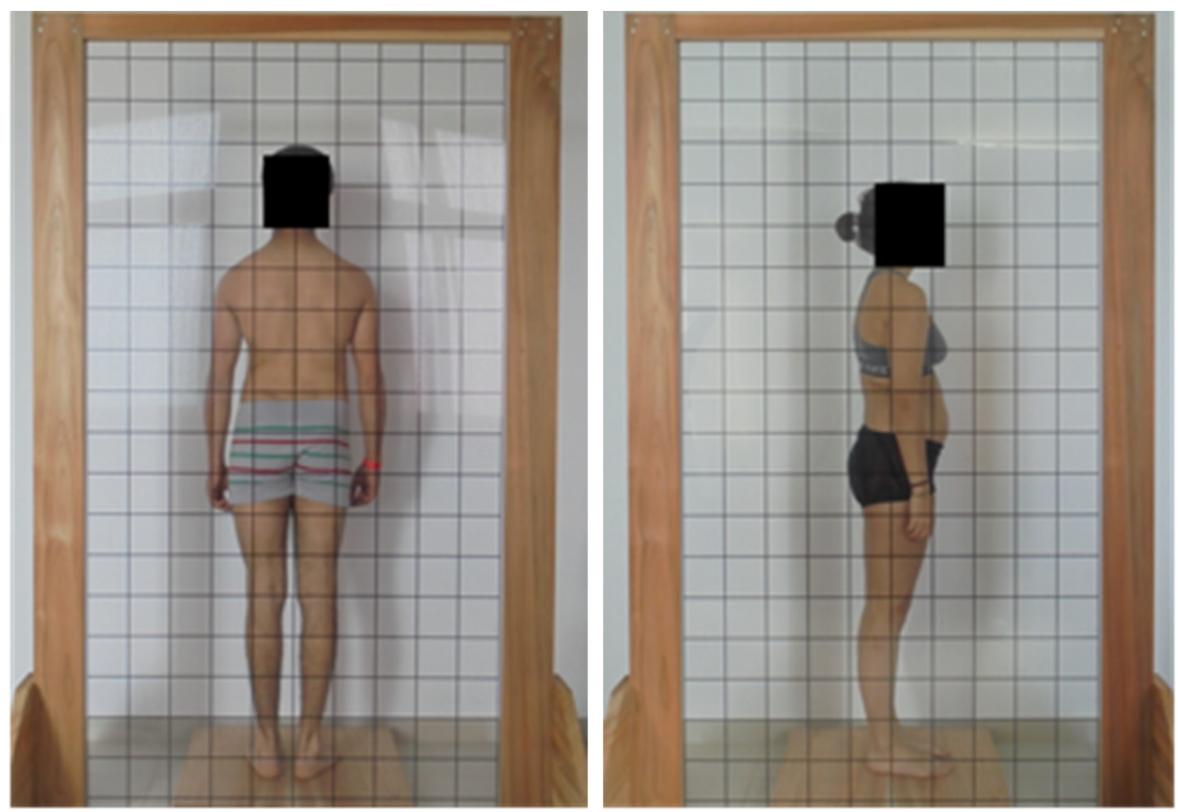

Figure 1. Full body pictures in the posterior view of the frontal plane and right lateral view of the sagittal plane.

The participants were assessed in the standing position in underwear [28]. Photogrammetry technique was used to collect digital images in the posterior view of the frontal plane and right lateral view of the sagittal plane (Figure 1). A Sony digital camera (Sonny, Ciber-shot DSC-W810, Tokyo, Japan) was placed $2.65 \mathrm{~m}$ distance from the symmetrograph and $0.85 \mathrm{~m}$ of heigh as in previous studies [29]. The distance between the camera and the symmetrograph allowed to perfectly identify the postural misalignments in the image. These two instruments were leveled through an air bubble level.

In the posterior view of the frontal plane the earlobes, shoulders, posterior superior and iliac spines, C3 to L5 vertebrae and the intergluteal fold alignment were evaluated. In the right view of the sagittal plane, the symmetry between external auditory canal, clavicular acromion, dorsal and lumbar cervical alignment, femoral trochanter, iliac crest and the pubic symphysis vertical alignment were assessed. These anatomical references defined a neutral postural profile, where any discordance in this alignment implied a postural misalignment. The Adams test allowed to evaluate the student's thoracolumbar curves with a trunk flexion, with palms held together, knees extended and feet together. The evaluation was made in a posterior position. The test was accounted positive when gibbosity or thoracolumbar curves were found.

\subsection{Statistical Analysis}

Descriptive statistics involving central tendency and dispersion parameters (mean and standard deviation) where used to characterize the selected variables. The Chi-Square test was used for the association between the head positioning and the shoulder girdle, the shoulder girdle and the dorsal spine, as well as between the lumbar spine and the pelvic girdle postural misalignments. The significance level taken into account for the differences found between the variables was $p<0.05$. The computer program used for the statistical analysis was the Statistical Package for Social Sciences (SPSS)—version 22.0.3.

\section{Results}

Postural misalignments were observed in all students. In the posterior view of the frontal plane, the highest prevalence's were observed in cervical scoliosis (51.6\%), left shoulder elevation (46.5\%) and in dorsal scoliosis (39.9\%). In right lateral view of the 
sagittal plane the most prevalent misalignments were the forward head posture $(76.1 \%)$, protracted shoulders (41.3\%) and pelvic anteversion (39.4\%) (Table 1).

Table 1. Summary of postural misalignments.

\begin{tabular}{|c|c|c|c|}
\hline & Postural Variables & Misalignments & Total $(\%)$ \\
\hline \multirow{11}{*}{ 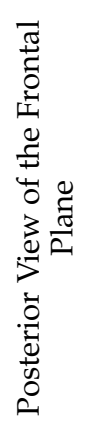 } & \multirow{2}{*}{ Head positioning } & Right lateral flexion & $39.9 \%$ \\
\hline & & Left lateral flexion & $35.2 \%$ \\
\hline & \multirow{2}{*}{ Scapular girdle } & Higher right shoulder & $28.6 \%$ \\
\hline & & Higher left shoulder & $46.5 \%$ \\
\hline & \multirow{3}{*}{$\begin{array}{l}\text { Cervical spine } \\
\text { Dorsal spine } \\
\text { Lumbar spine }\end{array}$} & Cervical scoliosis & $51.6 \%$ \\
\hline & & Dorsal scoliosis & $39.9 \%$ \\
\hline & & Lumbar scoliosis & $29.6 \%$ \\
\hline & \multirow{2}{*}{ Pelvic girdle } & Right pelvic tilt & $31.9 \%$ \\
\hline & & Left pelvic tilt & $7.0 \%$ \\
\hline & \multirow{2}{*}{ Adams test } & Positive right & $33.3 \%$ \\
\hline & & Positive left & $32.4 \%$ \\
\hline \multirow{12}{*}{ 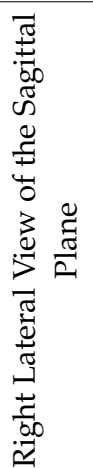 } & \multirow{2}{*}{ Head positioning } & Forward head posture & $76.1 \%$ \\
\hline & & Posterior head posture & $1.4 \%$ \\
\hline & \multirow{2}{*}{ Scapular girdle } & Protracted shoulders & $41.3 \%$ \\
\hline & & Retracted shoulders & $0.4 \%$ \\
\hline & \multirow{2}{*}{ Cervical spine } & Cervical rectification & $24.9 \%$ \\
\hline & & Cervical hyperlordosis & $4.7 \%$ \\
\hline & \multirow{2}{*}{ Dorsal spine } & Dorsal rectification & $0.9 \%$ \\
\hline & & Dorsal hyperkyphosis & $29.6 \%$ \\
\hline & \multirow{2}{*}{ Lumbar spine } & Lumbar rectification & $4.7 \%$ \\
\hline & & Lumbar hyperlordosis & $24.9 \%$ \\
\hline & \multirow{2}{*}{ Pelvic girdle } & Pelvic anteversion & $39.4 \%$ \\
\hline & & Pelvic retroversion & $0.9 \%$ \\
\hline
\end{tabular}

Regarding the comparison between the head position and the shoulder girdle (Table 2), forward head was associated with protracted shoulders in the right view of the sagittal plane $\left(X^{2}=13.294 ; p=0.010\right)$. The percentage of aligned shoulders was higher for subjects who presented the aligned head position $(85.7 \%)$ and lower for who presented forward head projection $(52.5 \%)$. In the posterior view of the frontal plane, the percentage of symmetrical shoulders was higher for the subjects who presented the aligned head position $(26.4 \%)$ without statistical significance.

Table 2. Percentage, frequency and chi-square test for analysis of the relationship between the head position and the shoulder girdle.

\begin{tabular}{|c|c|c|c|c|c|}
\hline \multicolumn{6}{|c|}{ Right Lateral View of the Sagittal Plane } \\
\hline & & Shoulder Girdle & & $X^{2}$ & $p$ \\
\hline Head position & Aligned shoulders & $\begin{array}{l}\text { Protracted } \\
\text { shoulders }\end{array}$ & $\begin{array}{l}\text { Retracted } \\
\text { shoulders }\end{array}$ & & \\
\hline Aligned & $85.7 \%$ & $14.3 \%$ & $0.0 \%$ & & 0.010 * \\
\hline Forward head & $52.6 \%$ & $46.9 \%$ & $0.6 \%$ & & \\
\hline Posterior head & $66.7 \%$ & $33.3 \%$ & $0.0 \%$ & 13.294 & \\
\hline
\end{tabular}

Legend: ${ }^{*} p<0.05$.

Regarding the comparison between the shoulder girdle and the dorsal spine (Table 3), protracted shoulders were related to dorsal hyperkyphosis in the right view of the sagittal plane $\left(X^{2}=9.562 ; p=0.048\right)$. The percentage of normal dorsal column was higher for subjects who revealed a shoulder girdle with aligned shoulders $(76.6 \%)$ and lower for protrusion $(60.2 \%)$. In the posterior view of the frontal plane, the percentage of dorsal scoliosis was higher for subjects who presented the shoulder girdle with right (55.7\%) and 
left (51.5\%) elevation and lower for symmetrical shoulders (37.7\%). However, no statistical significance was founded.

Table 3. Percentage, frequency and chi-square test for analysis of the relationship between the shoulder girdle and the dorsal spine.

\begin{tabular}{|c|c|c|c|c|c|}
\hline \multicolumn{6}{|c|}{ Right Lateral View of the Sagittal Plane } \\
\hline & & Dorsal Spine & & $X^{2}$ & $p$ \\
\hline \multirow{3}{*}{$\begin{array}{l}\text { Shoulder girdle } \\
\text { Aligned shoulders } \\
\text { Protracted } \\
\text { shoulders }\end{array}$} & Normal & Retification & Hyperkyphosis & & \multirow{4}{*}{0.048 * } \\
\hline & $76.6 \%$ & $1.6 \%$ & $21.8 \%$ & & \\
\hline & $60.2 \%$ & $0.0 \%$ & $39.8 \%$ & & \\
\hline $\begin{array}{l}\text { Retracted } \\
\text { shoulders }\end{array}$ & $100.0 \%$ & $0.0 \%$ & $0.0 \%$ & 9.562 & \\
\hline
\end{tabular}

Legend: ${ }^{*} p<0.05$.

The comparison between lumbar spine and the pelvic girdle (Table 4), in the posterior view of the frontal plane lumbar scoliosis was significantly more prevalent in subjects with posterior superior iliac spine's misalignment $\left(X^{2}=72.419 ; p<0.001\right)$ and in the right lateral view of the sagittal plane lumbar hyperlordosis was significantly related to the subjects with pelvic anteversion $\left(X^{2}=59.597 ; p<0.001\right)$ and lower to those with pelvic neutral position.

Table 4. Percentage, frequency and chi-square test for analysis of the relationship between the lumbar spine and the pelvic girdle.

\begin{tabular}{|c|c|c|c|c|c|c|}
\hline \multicolumn{7}{|c|}{ Posterior View of the Frontal Plane } \\
\hline & \multicolumn{4}{|c|}{ Lumbar Spine } & $X^{2}$ & $p$ \\
\hline Pelvic girdle & & Aligned & & Scoliosis & & \multirow{4}{*}{$<0.001 * *$} \\
\hline Neutral position & & $91.5 \%$ & & $8.5 \%$ & & \\
\hline Right tilt & & $39.7 \%$ & & $60.3 \%$ & & \\
\hline \multirow[t]{3}{*}{ Left tilt } & & $26.7 \%$ & & $73.3 \%$ & 72.419 & \\
\hline & \multicolumn{5}{|c|}{ Right Lateral View of the Sagittal Plane } & \\
\hline & \multicolumn{4}{|c|}{ Lumbar Spine } & $\mathrm{X}^{2}$ & $p$ \\
\hline Pelvic girdle & Normal & & Retification & Hyperlordosis & & \\
\hline Neutral position & $84.3 \%$ & & $8.7 \%$ & $7.1 \%$ & & \\
\hline Pelvic anteversion & $47.6 \%$ & & $0.0 \%$ & $52.4 \%$ & & $<0.001^{* *}$ \\
\hline Pelvic retroversion & $100.0 \%$ & & $0.0 \%$ & $0.0 \%$ & 59.597 & \\
\hline
\end{tabular}

\section{Discussion}

This work had as its main objective to assess significant differences in student's spine, scapular and pelvic alignment by visual scan analysis in PE class. It was hypothesized that the subjects would show high percentages of postural misalignments and that there is a relationship between its occurrences. This study detected high percentages of postural misalignments in all subjects. In the posterior view of the frontal plane the highest prevalence's were found in the head lateral flexion, shoulders level asymmetry, scoliosis and in gibbosity, whereas in the right view of the sagittal plane a forward head posture and protracted shoulders were mostly observed. The main findings in the relation between misalignments were that lumbar scoliosis was significantly more prevalent in subjects with posterior iliac crest's misalignment, forward head was significantly higher for the subjects who presented protracted shoulders and the later ones with dorsal hyperkyphosis. Lumbar hyperlordosis was also significantly more prevalent in subjects with pelvic anteversion. 
The choice for visual scan analysis in a symmetrograph results from a non-invasive method, with easy application in larger samples and with immediate feedback in PE classes [9]. The Adams test is by common consent recognized as primary basis for monitoring scoliosis and gibbosity $[5,27]$.

Postural assessment importance in school students is substantiated by the fact that there is a high prevalence of misalignments in all ages and school cycles [6-8,11,12]. It also seems evident that the body changes resulting from the growth process could cause postural imbalances $[8,11]$, as well as the fact that the postural habits acquired at these ages remain until adulthood [11,22]. Therefore, it is extremely important its early detection so that they can be corrected in a timely manner. PE Classes should develop exercises that not only consider these pathologies, but also contribute to their correction and normalization. It's also known that a school posture program improves ergonomic knowledge in adolescents $[11,12,30]$.

Regarding postural assessment, the misalignments were founded for the total sample. In the posterior view of the frontal plane, scoliosis was the most prevalent misalignment, being this finding more marked in the upper levels of the spine $[5,18,19,23]$. This phenomenon may be related to the pubertal growth body transformations [26], low muscle strength levels to balance external loads [21] or with the constant adoption of postures that involve prolonged trunk lateral flexion [29]. Shoulders level misalignments were the second most prevalent, with left shoulder elevation predominance $[3,13,31,32]$ probably due to the dominant side overuse $[14,33]$ and muscle strength low levels to support external loads. The often unilaterally excess of weight carried in the school backpacks could be related with this misalignment [21,22]. The lumbar scoliosis was statistically related with posterior iliac crests misalignments. In the right view of the sagittal plane, forward head posture was the most obvious misalignment [19,34], presumably related with the long periods of mobile phone usage [35], the use of low tables or highchairs [16] or also as a rebalance for the excess of weight carried in the backpack [16,21,22,36]. Protracted shoulders were the second most prevalent misalignment in our work $[3,7,31]$. However, these results were lower regarding most of the literature $[6,13,14,19]$. The protracted shoulders higher percentage was found in subjects with forward head posture. The dorsal hyperkyphosis high prevalence agreed with previous studies $[6,15,19]$ and was significantly higher for students with protracted shoulders. That may be due to the possible relation with the high prevalence of forward head posture [37]. The lumbar hyperlordosis was observed with lower percentage in comparison to other studies [13-15,19]. Pelvic anteversion was the third most prevalent misalignment in the sagittal plane, although presented a lower prevalence than that we identify in other consulted works $[3,13,14]$, being significantly higher for subjects who revealed hyperlordosis [13].

The significant postural misalignments prevalence for the total sample emphasized the importance of assessing posture in PE Classes. The main findings of this work showed that lumbar scoliosis was more prevalent in subjects with iliac crest's asymmetry. The forward head posture was significantly related to protracted shoulders and the protracted shoulders were more marked in students with dorsal hyperkyphosis. The lumbar hyperlordosis was more prevalent in subjects with pelvic anteversion. The present study was based on data collected from students from a specific geographical location condition and the results cannot be generalized for the Portuguese student population. For future studies, it is important to carry out a logistic regression to better understand the relationship between postural misalignments. We also suggest conducting a similar methodology (postural analysis) as longitudinal analysis and assessing youth's biological age. Finally, it is important to assess relationships between postural misalignments and pain events.

\section{Conclusions}

It was possible to attest a high number of postural misalignments in students. The highest prevalence was noted in the head posture, followed by protracted shoulders and horizontal alignment, scoliosis events and pelvic anteversion cases. The lumbar scoliosis 
was significantly related to the iliac crest's asymmetry, forward head posture was more prevalent in subjects with protracted shoulders, protracted shoulders were related to dorsal hyperkyphosis and lumbar hyperlordosis was more marked in subjects with pelvic anteversion. Postural education should be a priority for schools and the importance of postural assessment in PE Classes should be highlighted.

Author Contributions: Conceptualization, J.P.G., P.F. and E.C.; methodology, J.P.G., P.F. and E.C.; software, J.P.G., P.F., J.R. and E.C.; validation, J.P.G., P.F. and E.C.; formal analysis, J.P.G., P.F., J.R. and E.C.; investigation, J.P.G., P.F. and E.C.; resources, J.P.G., P.F. and E.C.; data curation, J.P.G., P.F. and E.C.; writing —original draft preparation, J.P.G.; writing-review and editing, J.P.G., P.F., J.R. and E.C.; visualization, J.P.G., P.F. and E.C.; supervision, P.F. and E.C.; project administration, J.P.G., P.F. and E.C.; funding acquisition, P.F., J.R. and E.C. All authors have read and agreed to the published version of the manuscript.

Funding: This work is supported by the Douro Higher Institute of Educational Sciences and the Portuguese Foundation for Science and Technology, I.P. (project UIDB04045/2021).

Informed Consent Statement: Informed consent was obtained from all the subjects involved in the study. The study was conducted according to the guidelines of the Declaration of Helsinki, and approved by the Institutional Review Board of Education Regional Direction (protocol code $\mathrm{n}^{\circ}$ DSP/15-29 and date of approval 28 October 2016).

Data Availability Statement: Data available on request to corresponding author.

Acknowledgments: The authors would like to thank the group of schools of Santa Maria, the school parents' association, the Vila do Porto Health Centre and the Education Regional Direction to collaborate with this research. All individuals included in this section have consented to the acknowledgement.

Conflicts of Interest: The authors certify that there is no conflict of interest with any financial organization regarding the material discussed in the manuscript.

\section{References}

1. Kisner, C.; Colby, L. Therapeutic Exercise: Foundations and Techniques; F. A. Davis Company: Philadelphia, PA, USA; Baltimore, MA, USA, 2007.

2. Patel, K. Corrective Exercise: A Practical Approach; Hodder Arnold: London, UK, 2005.

3. Pinto, H.; Lópes, R. Postural Problems in Students of the Paranoá High School Center-Brasilia 2001. Available online: http: / / www.efdeportes.com (accessed on 13 November 2017).

4. Nowotny-Czupryna, O.; Krzysztof, C.; Bąk, K.; Wróblewska, E.; Rottermund, J. Postural Habits of Young Adults and Possibilities of Modification. Ortop. Traumatol. Rehabil. 2012, 1, 9-21. [CrossRef]

5. Minghelli, B. School Screening: The Importance of Early Detection of Scoliotic Postures in Adolescents from Silves Schools, Algarve. Rev. Port. De Saúde Pública 2008, 26, 61-68.

6. Ferronatto, A.; Candotti, C.; Silveira, R. The Incidence of Changes in Static Scapular Waist Balance in Children Between 7 and 14 Years. Rev. Mov. 1998, 5, 24-30.

7. Santos, C.; Cunha, A.; Braga, V.; Saad, I.; Ribeiro, M.; Conti, P.; Oberg, T. Postural Misalignments Occurrence in Elementary School Students from Jaguariúna, São Paulo. Rev. Paul. Pediatr. 2009, 27, 74-80. [CrossRef]

8. Klusener, G.; Porto, D. Physiotherapy in Schools: Postural Assessment in Children from 6 to 11 Years Old. Rev. Inspirar. Mov. Saúde 2014, 6, 6-12.

9. Alves, M.; Marinho, D.; Carneiro, D.; Alves, J.; Forte, P.; Nevill, A.; Morais, J. A Visual Scan Analysis Protocol for Postural Assessment at School in Young Students. Int. J. Environ. Res. Public Health 2020, 17, 2915. [CrossRef]

10. Gouveia, J.; Forte, P.; Coelho, E. Study of Postural Misalignments Between Sex, School Cycle and Physical Activity. J. Hum. Sport Exerc. 2020, 1-11, in press. [CrossRef]

11. Desouzart, G.; Gagulic, S. Analysis of Postural Changes in 2nd Cycle Students of Elementary School. J. Spine 2017, 6, 1000357. [CrossRef]

12. Rosa, B.; Furlanetto, T.; Noll, M.; Sedrez, J.; Schmit, E.; Candotti, C. 4-Year Longitudinal Study of the Assessment of Body Posture, Back Pain, Postural and Life Habits of Schoolchildren. Mot. Edições Desafio Singul. 2017, 13, 3-12. [CrossRef]

13. Minghelli, B.; Abílio, F.; Góis, A.; Timóteo, A.; Florença, H.; Lóia, N.; Jesus, T.; Serra, F.; Duarte, M. Prevalence of Postural Changes in Children and Adolescents in Schools in the Algarve. Saúde Tecnol. 2009, 4, 33-37.

14. Peliteiro, D.; Festas, C.; Lourenço, M. Analysis of Postural Changes in Schoolchildren. Rev. Da Fac. De Ciências E Saúde 2010, 7, 354-366. 
15. Noll, M.; Rosa, B.; Candotti, C.; Furlamento, T.; Gontijo, K.; Sedrez, J. Postural Changes in Elementary School Students at a School in Teutônia. Revista Brasileira de Ciência e Movimento 2012, 20, 32-42. [CrossRef]

16. Braccialli, L.; Vilarta, R. Aspects to be Considered in the Development of Prevention and Orientation Programs for Postural Misalignments. Rev. Paul. Educ. Fís. 2000, 14, 16-28.

17. Verderi, E. The Importance of Postural Assessment 2003. Available online: http:/ / www.efdeportes.com (accessed on 11 December 2017).

18. Minghelli, B.; Oliveira, R.; Nunes, C. Postural Habits and Weight of Backpacks of Portuguese Adolescents: Are they Associated with Scoliosis and Low Back Pain? Work 2016, 54, 197-208. [CrossRef]

19. Tobar, N. Postural Characteristics of José Maria Obando School Children from the City of Popayán. 2004. Available online: http:/ / www.efdeportes.com (accessed on 19 November 2017).

20. Lafeta, J.; Gondin, J.; Durães, G.; Junior, E.; Silveira, M. Biophotogrammetric Analysis of the Main Postural Changes of the Spine in Schoolchildren. 2013. Available online: http:/ / www.efdeportes.com (accessed on 22 December 2017).

21. Barbosa, J.; Marques, M.C.; Izquierdo, M.; Neiva, H.P.; Barbosa, T.M.; Ramírez-Vélez, R.; Alonso-Martínez, A.M.; García-Hermoso, A.; Aguado-Jimenez, R.; Marinho, D.A. Schoolbag Weight Carriage in Portuguese Children and Adolescents: A Cross-Sectional Study Comparing Possible Influencing Factors. BMC Pediatr. 2019, 19, 157. [CrossRef]

22. Sedrez, A.; Da Rosa, M.; Noll, M.; Medeiros, F.; Candotti, C. Risk Factors Associated with Spinal Structural Changes in the Spine in Children and Adolescents. Rev. Paul. Pediatr. 2015, 33, 72-81. [CrossRef]

23. Braz, H.; Borges, M. The Relevance of Postural Assessment in Schools. Coleção Pesqui. Em Educ. Física 2007, 6, 25-32.

24. Moreira, J.; Cornelian, B.; Lopes, C. The Importance of Good Postural Positioning in Schoolchildren-The Role of the Physical Education Teacher. Rev. Uningá Rev. 2013, 16, 42-48.

25. Sallis, J.; McKenzie, T.; Beets, M.; Beighle, A.; Erwin, H.; Lee, S. Physical Education's Role in Public Health: Steps Forward and Backward Over 20 Years and HOPE for the Future. Res. Q. Exerc. Sport 2012, 83, 42-48. [CrossRef]

26. Martellli, R.; Traebert, J. Descriptive Study of Postural Changes in the Spine in Schoolchildren from 10 to 16 Years of Age. Rev. Bras. De Epidemiol. 2004, 9, 87-93.

27. Ferreira, D.; Suguikawa, T.; Pachioni, C.; Fregonesi, C.; Camargo, M. School Scoliosis Screening: Measure for Early Diagnosis. Rev. Bras. Crescimento Desenvolv. Hum. 2009, 19, 357-368.

28. Kendall, F.; McCreary, E.; Provance, P.; Rodgers, M.; Romani, W. Muscles Testing and Function with Posture and Pain; Lippincott Williams \& Wilkins: Philadelphia, PA, USA, 2005.

29. Santos, J.; Moro, A.; Cezar, M.; Reis, P.; Luz, J.; Reis, D. Portland State University Postural Assessment Method Description. Fisioter. Bras. 2005, 6, 392-395. [CrossRef]

30. Minghelli, B. Postural Habits in Adolescents: The Influence of a School Physiotherapy Program on Improving the Knowledge of Postures. Int. J. Adolesc. Med. Health 2020, 20190138. [CrossRef]

31. Biava, J.; Lima, D. Postural Education at School: An Integrative Approach to the Educational Development Program. 2011. Available online: http:/ / www.diaadiaeducacao.pr.gov.br/portals/pde/arquivos / 23718.pdf?PHPSESSID=2010012708223041 (accessed on 1 October 2018).

32. Preto, L.; Santos, A.; Rodrigues, V.; Quitério, N.; Pimentel, M.; Manrique, G. Photogrammetry Analysis of Posture and Associated Risk Factors in Schooled Children and Adolescents. Rev. De Enferm. Ref. 2015, 5, 31-40. [CrossRef]

33. Hall, S. Basic Biomechanics. In Rio De Jan. Guanab. Koogan; McGrawHill Collrgr: Singapore, 2016. Available online: https: //www.amazon.com/Basic-Biomechanics-Susan-J-Hall/dp/0072462043 (accessed on 1 October 2018).

34. Silva, P. Postural Changes in Children Attending Municipal Schools in the City of Salvador. Bahia. Rev. Diálogos Ciência. 2016, $16,16-30$.

35. Jung, S.; Lee, N.; Kank, K.; Kim, K.; Lee, D. The Effect of Smartphone Usage Time on Posture and Respiratory Function. J. Phys. Ther. Sci. 2016, 28, 186-189. [CrossRef]

36. Oshiro, V.; Ferreira, P.; Costa, R. Postural Changes in Schoolchildren: A Literature Review. Rev. Bras. De Ciências E Saúde 2007, $3,15-22$.

37. Johnson, J. Postural Correction: Hands-On Guide for Therapists; Human Kinetics: Champaign, IL, USA, 2016. 